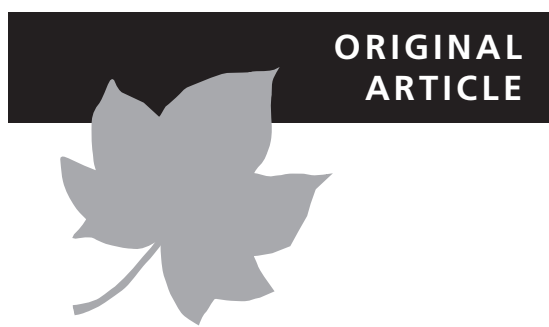

\title{
Climate change expected to drive habitat loss for two key herbivore species in an alpine environment
}

\author{
M. Parida ${ }^{1 \star}$, A. A. Hoffmann ${ }^{1}$ and M. P. Hill ${ }^{2}$
}

${ }^{1}$ School of Biosciences, Bio 21 Institute, The University of Melbourne, Melbourne, Australia, ${ }^{2}$ Centre for Invasion Biology, Department of Conservation Ecology and Entomology, Faculty of AgriSciences, Stellenbosch University, South Africa

${ }^{*}$ Correspondence: Manaswini Parida, Level 2, School of Biosciences, Bio 21 Institute, 30 Flemington Rd, Parkville, Melbourne, VIC 3010, Australia.

E-mail: mparida@student.unimelb.edu.au

\section{ABSTRACT}

Aim Our first aim was to determine the environmental factors associated with two native Australian Lepidoptera species, Lomera caespitosae and Oncopera alpina, key herbivores of alpine and subalpine Poa grasses. Both species have been associated with areas of extensive grass death in Australian alpine regions, possibly affecting vegetation succession and recovery. Our second aim was to generate and evaluate potential distributional changes for both these moths and their host plants under scenarios of climate change.

Location Alpine regions in south-eastern Australia.

Methods We surveyed alpine regions in south-eastern Australia to compile presence-absence datasets for both moth species. We constructed ecological niche models from our survey data, in addition to predicting distributions of suitable host-plant species for the moths. Grass damage sites attributed to the moths were used additionally as independent test datasets to validate model performance. Future effects on species distributions under climate change scenarios were then investigated.

Results The environmental factors affecting distributions differed between the moth species; for example, precipitation variables appeared to be important for L. caespitosae, while low winter-spring temperatures were expected to limit O. alpina. The findings were related to the presence of grass damage, which was greater in areas where species distributions overlapped. A declining trend in suitability was predicted for both herbivore species under climate change, while Poa spp. distributions were expected to be less influenced by climate change.

Main conclusions The distributions of both moth species are more likely to be restricted by climate than host-plant availability. Predicted climate change effects are likely to put $L$. caespitosae under greater immediate risk of local extinction than O. alpina as a result of large areas of habitat loss by 2050 .

\section{Keywords}

Alpine moths, Australian Alps, biotic interaction, climate change, ecological niche modelling, grass deaths, Lomera caespitosae, Oncopera alpina, Poa.

\section{INTRODUCTION}

There has been increasing interest in predicting the effects of climate change on alpine plant and animal communities, because of both the perceived sensitivity of alpine species to drought and thermal extremes, and the vulnerability of many unique alpine communities that are restricted to small areas (Good, 2008; Gottfried et al., 2012; Thuiller et al., 2014). Climate change is expected to lead to extinctions of species from higher elevation communities as suitable climate space for those species disappears. Within alpine environments, shifts in the distribution of herbivorous insects using specific plant hosts may be particularly responsive to climate change (Hodkinson \& Bird, 1998; Araújo \& Luoto, 2007; BareaAzcón et al., 2014), either directly as a consequence of shifts in host-plant distributions that limit insect distributions (Hanspach et al., 2014), or because of indirect effects such as altered plant herbivore defences (Rasmann et al., 2014). With 
predictions of range contraction or range shifts of alpine plant species under climate change (Walther et al., 2005; Gottfried et al., 2012), it is important to understand the extent to which host-related effects and other factors limit insect distributions.

To explore host plant-herbivore distributions and responses to climate change, ecological niche models (ENMs) have proved to be useful tools for characterizing species-climate relationships, which can then be projected onto future climate scenarios, and these have been successfully applied in alpine environments (Parolo et al., 2008; Rinnhofer et al., 2012). While the correlative nature of ENMs means that interactions and other ecological processes are often implicitly incorporated through the use of distribution data (Elith \& Leathwick, 2009), the role of non-climatic factors that may mediate species responses to climate change are increasingly being incorporated explicitly into ENMs for alpine communities (Parolo et al., 2008). Such factors may include topography, land cover and soil data (Parolo et al., 2008; Eskildsen et al., 2013) or processes including competitive or facilitative interactions with species of the same or adjacent trophic levels (Heikkinen et al., 2007; Hof et al., 2012), resulting in changing community composition and driving range shifts (Van der Putten et al., 2010; Walther, 2010). Such interactions are likely to play important roles in the response of alpine species to climate change, and can be incorporated into models to improve predictions of distribution shifts at different spatial levels (Wisz et al., 2013; Araújo \& Rozenfeld, 2014). The predictive ability of ENMs is also constrained by the availability of data, including both accurate species survey records and climate layers at an appropriate level of resolution (Araújo et al., 2005; Osborne \& Leitão, 2009). High-resolution layers allow for greater climatic heterogeneity to be incorporated into ENMs and may help to identify potential refugia (Randin et al., 2009; Willis \& Bhagwat, 2009).

The Australian Alps are unique in sustaining an alpine environment at elevations considered to be relatively low by world standards, as a result of its geo-climatic position (Pickering \& Armstrong, 2000; Hughes, 2011). This environment is considered to be particularly vulnerable to climate change (Hennessy et al., 2003). Projected climate trends for the 21st century point to the disappearance of many niches (Williams et al., 2007), leading to the likelihood of species extinction, especially for species restricted to high elevations and having limited geographical ranges (Good, 2008; Hughes, 2011).

We considered the probable effects of climate change on two poorly known but important native Australian alpine Lepidoptera, Lomera caespitosae Oke (Psychidae; alpine case moth; Fig. 1a) and Oncopera alpina Tindale (Hepialidae; alpine grass grub; Fig. 1b), which represent dominant larval herbivores of alpine snow grass (Poa spp., Poaceae). Because of their selective feeding on Poa spp. and observed widespread distribution (Chadwick, 1966), larvae of either or both species have often been considered responsible for widespread Poa deaths across Victorian and New South Wales alpine regions (McKeown, 1951; Carr \& Turner, 1959;
Chadwick, 1969; Green \& Osborne, 1994; Edwards, 2002). Grass deaths allow the establishment of other vegetation, including shrubs and forbs, which require open areas to develop (Williams et al., 2014). These moth species may therefore play a role in creating vegetation heterogeneity within the alpine area.

In this study, we describe the potential role of plant-insect interactions in the current and predicted distribution of the two alpine moths, using an ENM framework. We examined model predictions to identify areas of overlapping climate space between the distributions of the moths and their host alpine grasses (Poa spp.) to identify suitable climate space under present and future (2030, 2050 and 2070) scenarios. This framework allowed us to ask three main questions. (1) Does climate or host availability play a greater role in limiting both moth species' distributions? (2) Are moth models able to predict areas of grass death occurrences? (3) Will habitat suitability for these species decrease under future climate change?

\section{MATERIALS AND METHODS}

\section{Data collection}

Surveys of the sessile larval stage of the moths were conducted during the summers of 2010 and 2011 in alpine and subalpine zones of the Bogong High Plains area of Victoria and the Kosciuszko-Kiandra region of New South Wales (NSW), Australia. Surveys involved a standardized 30-40min search at each site for larval activity around Poa tussocks, where larvae form camouflaged structures (Fig. 1a,b). The presence of $L$. caespitosae was determined from lancetshaped cases that the larvae build after hatching from dead grass (Poa spp.) and silk (Fig. 1a); these remain consistent throughout their growing period irrespective of raw materials. The presence of $O$. alpina was recorded through observation of aboveground grassy extensions of the belowground soil tunnel, also made out of dead grass (Poa spp.) blades coarsely combined with silk, in a circular fashion perpendicular to the length of the tunnel (Fig. 1b). Occasionally additional vegetation was incorporated for aboveground tunnel building, but the pattern remained the same. The morphology of the cast pupal cases that adult O. alpina leave behind after hatching (Fig. 1b) also helped field identification. Species presence was recorded above $700 \mathrm{~m}$ a.s.l., although the two species were never found on Poa below $1000 \mathrm{~m}$. We recorded species at $\geq 250-\mathrm{m}$ intervals (except for a few records at the top and bottom of mountains, which were recorded at a 100-m elevation interval). Geo-referenced data including elevation data were obtained with a hand-held GPS receiver (Magellan $\$ eXplorist, MiTAC International Corporation, Santa Clara, CA, USA).

\section{Modelling framework}

We employed a framework that incorporated two correlative ENM approaches, appropriate for the type of data available 

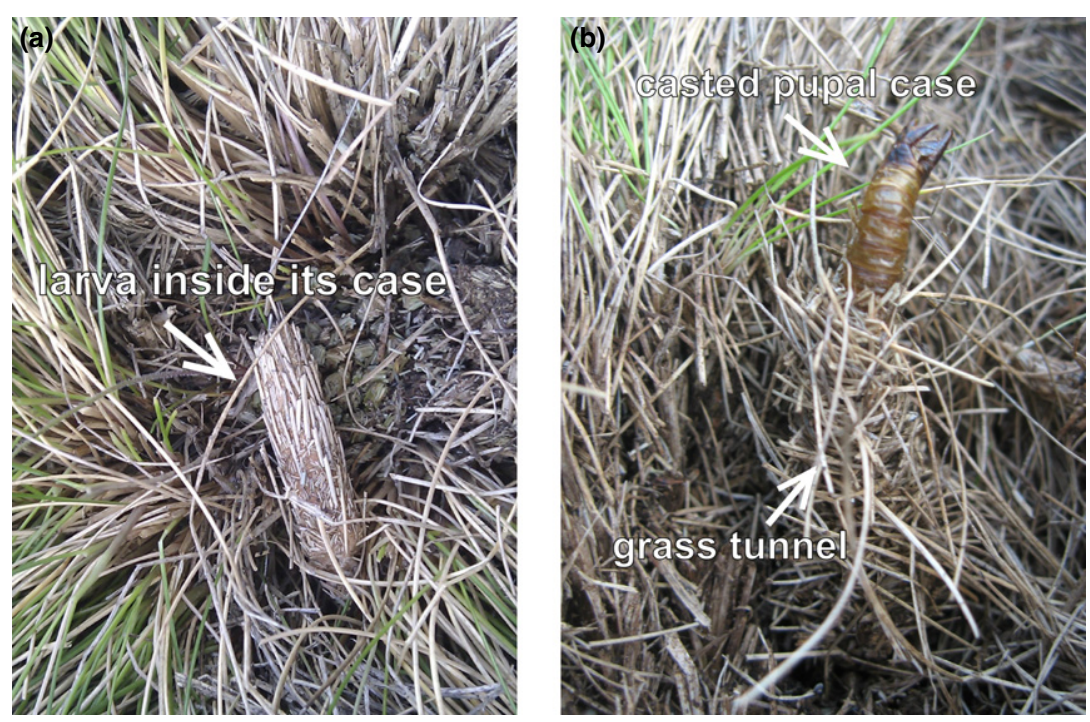

Figure 1 Field identification features of two Australian alpine Lepidoptera species. (a) Lomera caespitosae mature larva, inside its distinctly ornate case built of silk and dead Poa grass. (b) Oncopera alpina grass tunnel (aboveground extension of underground soil tunnel) coarsely made out of silk and dead Poa grass, with cast pupal case at its upper end. to us. We modelled the host plants and moths separately and then examined the effect of including host-plant model predictions to mask moth model predictions (i.e. allowing moths to occur only within suitable host-plant climate space). Host-plant species were modelled individually using the presence-background method with Maxent 3.3.3.k (Phillips, 2010) across a large geographical area (Fig. 2) and then merged into composite maps (see Fig. S1 in Appendix S1 of the Supporting Information) to represent the available host range, specific for each moth species based on their observed feeding choices of Poa spp. This framework was developed based on selecting appropriate backgrounds (or geographical areas), environmental predictors (or covariates), constructing appropriate correlative models and then projecting those models onto future climate surfaces.

\section{Background selection}

We selected a background that represented areas higher than $700 \mathrm{~m}$ a.s.l. in south-eastern Australia, reflecting a wide range of environmental conditions and accessible areas for both host plants (Poa spp.; Walsh \& Entwisle, 1994; Wilson, 2009) and moths (Barve et al., 2011), as well as providing a buffer zone of approximately $300 \mathrm{~m}$ beyond (lower elevation) known occurrences. For modelling moth species, we restricted our study area to regions of Australia within the states of Victoria and NSW (Fig. 2) between $145-150^{\circ}$ E and $35-38^{\circ} \mathrm{S}$, based on occurrence data (Elith et al., 2011).

\section{Environmental predictors}

For the moth models we chose an initial predictor variable set of 19 bioclimatic layers built in ANUCLIm 6.1 (Fenner School of Environment and Society, Australian National University, Acton, Australia), representing means and trends of temperature and precipitation. These variables were unprojected and reflected a grid cell resolution of $250 \mathrm{~m} \times 250 \mathrm{~m}$ at the equator, to match fine-scale sampling efforts better.
Correlation estimates for all pairwise combinations of the 19 predictor layers were calculated in ENMTools 1.3 (http:// enmtools.blogspot.com.au, accessed August 2012) (Warren et al., 2010). The full set of predictors was included in boosted regression tree (BRT) models (see below), to assess model contribution and high correlation $(r \geq 0.8)$ between predictor pairs. A subset $(n=5)$ of the most important contributing predictor variables with low pairwise correlations was used in the final models.

\section{Building composite host-range maps}

Both moth species have different host Poa spp. associations (M. Parida, unpublished data), so we constructed composite maps matching host-plant preference of each moth species. For L. caespitosae, three Poa species (Poa hiemata Vickery, Poa costiniana Vickery and Poa phillipsiana Vickery; Poa3) were selected, whereas for O. alpina, five Poa species ( $P$. hiemata, P. costiniana, P. phillipsiana, Poa fawcettiae Vickery and Poa hothamensis var. hothamensis N.G. Walsh, hereafter referred to as P. hothamensis; Poa5) were selected. Coverage of Poa5 and Poa3 thus represented the maximal habitat range for each moth species (Fig. S1).

\section{Moth modelling}

BRT have been applied successfully to a range of different species (Buston \& Elith, 2011; Mellin et al., 2012; Jaeschke et al., 2013), particularly because of their strong predictive performance and reliable identification of relevant variables and interactions (Elith et al., 2008). Moth distribution models were fitted in R 3.0.2 ( $\mathrm{R}$ Core Team, 2013) using GBM package version 2.1 (Ridgeway et al., 2013) implemented through the Dismo package (Hijmans et al., 2013). Model settings included optimization of tree complexity (tc) and learning rate (lr), such that predictive deviance was minimized without over-fitting. Initial model performance and predictions revealed that we did not have enough true 


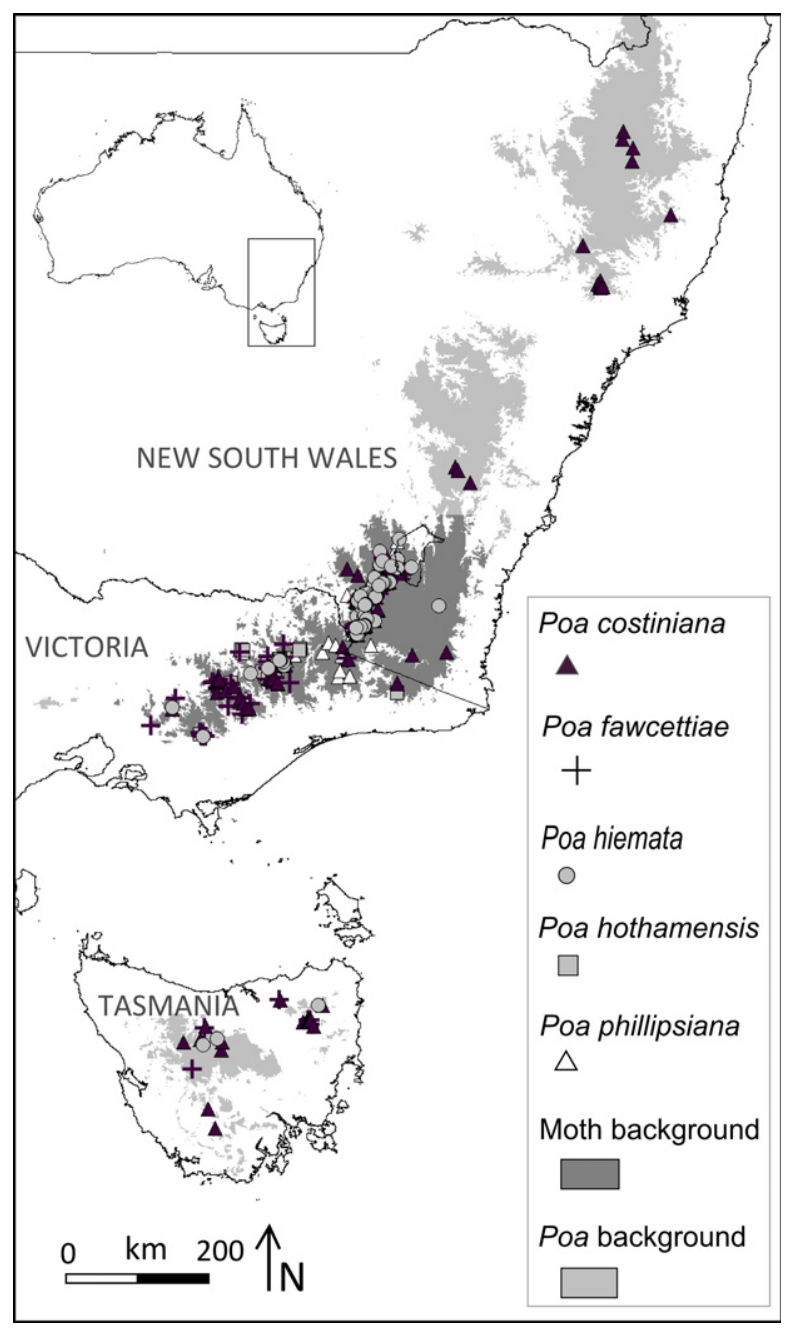

Figure 2 Backgrounds defined for modelling Australian alpine host-plant species (Poa spp.; represented by lighter shading) and two herbivore Lepidoptera species, Lomera caespitosae and Oncopera alpina (represented by darker shading), showing presence records for individual host Poa spp. All shaded areas represent high-elevation regions above $700 \mathrm{~m}$ a.s.l. used as a mask. The rectangular box in the inset shows the location of the study area on a map of Australia.

absence data to calibrate our models sufficiently. To address this issue we randomly sampled ( $n=1000$ or until cell coverage) in nearby similar environments (between $700 \mathrm{~m}$ and $1000 \mathrm{~m}$ ) where we had not found either of the moth species, and incorporated them as pseudo-absence data to increase the number of observations. We examined the effects of adding these pseudo-absences through model sensitivity rates. Once the optimal combination of tc and lr was found, the predictive performance was evaluated further using a 10-fold cross-validation procedure. Measures of model performance included predictive deviance expressed as a percentage of total deviance, and discrimination ability measured as the area under the receiver operating characteristic curve (AUC) in each model (e.g. Buston \& Elith, 2011). Fitted functions were visualized using partial dependence plots that showed the predictor effect on the species response after accounting for the average effect of other variables in the model. We ran the moth models first without host-plant layers and then restricted predictions to binary suitable/non-suitable climate space from each composite (Poa3 and Poa5) map for comparison.

For model evaluation we used five $k$-fold partitions on the initial datasets (80:20 split of presences and true absences) and then added the pseudo-absences to the training dataset for each respective partition. We examined $\mathrm{AUC}_{\mathrm{TEST}}$ on the held-out fold (i.e. building a model per iteration on four of the $k$-fold partitions and obtaining an AUC score using the remaining fold for testing; Hill et al., 2012), and repeated this process 10 times to give a total of $50 \mathrm{AUC}_{\mathrm{TEST}}$ values per species. As we had increased the number of observations for the models through pseudo-absences and inherently inflated the AUC statistic, we examined model performance further through sensitivity and specificity rates encapsulated in the true skill statistic (TSS) (Allouche et al., 2006). The TSS is threshold-specific so model performance was evaluated at maximum sensitivity plus specificity (Liu et al., 2013) across the same folds generated for $\mathrm{AUC}_{\mathrm{TEST}}$.

\section{Ecological niche comparison}

To examine similarity in niches between the two moth species, we employed the niche identity test within ENMTools to compare habitat suitability scores based on known occurrence points. For this test to be consistent, we took the final predictor variables that were used for both moth species independently and combined them into a single variable set (for additional details, see Warren et al., 2008, 2010). The aim of the niche identity was to determine whether ENMs generated from the two species were more different than expected if they were drawn from the same underlying distribution in numbers equalling the empirical data. The process of pooling empirical occurrence points for the two species and randomizing sampling (repeated 100 times) was performed in ENMTools. Similarity scores (Schoener's D) were compared between ENMs built from known occurrences and the distribution of similarity scores of ENMs built from randomly drawn pooled occurrences, to test whether they were more different than expected. Additionally, we performed a principal components analysis (PCA) to summarize the information at occurrence points across these eight predictor variables, and visually examined the overlap within environmental space between the moth species and across the study background.

\section{Detecting grass-damage sites}

Within the Australian alpine environment, grass death caused by moth attack occurs sporadically (Chadwick, 1966). In affected areas, only Poa spp. are targeted and damage is exhibited by loose grass cut at sheath level, with a bleached appearance after winter snow. Data for 
grass-death occurrences included field recordings made by the authors and others (see Acknowledgements), including published accounts (Chadwick, 1966), from early 1943 to 2012. Damage sites with an expanse $>50 \mathrm{~m}^{2}$ were included. We used this grass-damage information (data resolution matched to climatic resolution) (see Fig. S2 in Appendix S2) as an independent test dataset to evaluate further our complete moth models by recording the predictive ability at damage sites as both $\mathrm{AUC}_{\mathrm{TEST}}$ and omission error rates (sensitivity - 1).

\section{Climate change predictions}

To examine potential changes under future climate change, we projected models into the A1FI (fossil fuel intensive) emission scenario (IPCC, 2007) for 2030, 2050 and 2070. This was performed separately for each Poa species and then composite maps were made as before for each projection scenario. Both moth species models were projected onto future climate surfaces with and without the corresponding projected composite host Poa spp. map as a mask. We measured niche overlap in predictions of habitat suitability between current and future ENM projections, using Schoener's D statistic in ENMTools (Warren et al., 2010). An overlap range from 0 (completely discordant projections) to 1 (identical projections) was calculated by taking the difference in suitability score between model predictions at each grid cell (Warren et al., 2008, 2010).

\section{RESULTS}

\section{Moth modelling}

As a result of our survey effort, 61 presences and 52 absences were recorded for L. caespitosae, and 126 presences and 25 absences for O. alpina (see Fig. S2a,b in Appendix S2 for species presences). The optimal settings that achieved minimum predictive deviance with 10 -fold cross-validation in both species were $\mathrm{tc}=6, \mathrm{lr}=0.005$, using a bag fraction (the proportion of data selected at each step; see Elith et al., 2008, for details) of 0.5 .

Predictor variables and combinations of these variables contributed differently (see Fig. S3a,b in Appendix S3) to the two moth ENMs, indicating that the species responded differently to shared climatic predictors. Habitat suitability for $L$. caespitosae appeared to be driven by a multitude of factors, such as mean temperature of wettest quarter (BIO08), precipitation of driest period (BIO14), minimum temperature of coldest period (BIO06) and mean temperature of warmest quarter (BIO10), explaining $88.8 \%$ of the model behaviour. However, for O. alpina BIO08 alone explained $81.8 \%$ of the model variance. Species response to low mean temperatures during the wettest quarter (JulySeptember) (BIO08) increased positively below $3{ }^{\circ} \mathrm{C}$ for L. caespitosae, reaching the highest suitability at $0{ }^{\circ} \mathrm{C}$, whereas for O. alpina suitability increased below $5{ }^{\circ} \mathrm{C}$, reach- ing its highest point at $0{ }^{\circ} \mathrm{C}$. High precipitation $(>15 \mathrm{~mm})$ values during the driest period (BIO14) were suitable for both species; however, the contributory effect of BIO14 was higher for L. caespitosae (22.6\%) compared with O. alpina $(6.9 \%)$. Habitat suitability decreased with rising mean temperature $\left(>15^{\circ} \mathrm{C}\right)$ of the warmest quarter (December-February) (BIO10) and minimum temperature $\left(>-4{ }^{\circ} \mathrm{C}\right)$ of the coldest period (BIO06) for L. caespitosae. For O. alpina, habitat suitability was affected least by climatic variables such as maximum temperature of warmest period (BIO05) (4.3\%) and precipitation values during the wettest period (BIO13) $(2.5 \%)$.

We found that the addition of pseudo-absence data for each species improved the fit of the data (when examined spatially) and predictive performance (increased AUC values). Additionally, sensitivity increased with the addition of pseudo-absences, coupled with a decrease in the modelled threshold at which maximum sensitivity plus specificity was obtained (Table 1). The final models yielded high $\mathrm{AUC}_{\mathrm{TEST}}$ scores $(0.82 \pm 0.01$ and $0.94 \pm 0.01$ for $L$. caespitosae and O. alpina, respectively) supported by good to high TSS scores $(0.59 \pm 0.13$ and $0.87 \pm 0.07$ for L. caespitosae and O. alpina, respectively) (Table 2 ). Importantly, our models also showed new areas of suitable climate space for further sampling efforts. For L. caespitosae these included parts of the Snowy Mountains in the north and lower southern extremes of the Alpine National Park, including Reynard and Nap Nap Marra in Victoria. New suitability regions for O. alpina included the Bimberi Nature Reserve bordering NSW and Australian Capital Territory (ACT) and parts of the Snowy Mountains in Victoria.

\section{Comparing ecological niche models between moths}

The niche identity test between moth species (Schoener's $D=0.6$ ) suggested that the observed niche overlap score under the cumulative effect of all final predictor variables was no different than expected if it had been drawn from the same underlying distribution (Fig. 3a). This implied an absence of any significant ecological differences between the two species' niches. The PCA supported overlapping environmental conditions between the species, but additionally the species appeared to occupy specific environmental space within the study area and in relation to the Poa5 mask (Fig. 3b).

\section{Moth distribution and grass damage}

By using Poa spp. damage sites (Fig. S2) as an independent test dataset for both final moth models, very high AUC values were obtained for each species (L. caespitosae 0.92, $O$. alpina 0.98). Omission error rates across these damage sites at a threshold of least training presence (sensitivity $=1$; obtained from the complete datasets across final model scores; see Table 1) were low for O. alpina (0.04), whereas for L. caespitosae they were higher (0.17; Table 2). 
Table 1 Predictive performance of boosted regression tree (BRT) models with and without additional pseudo-absence data for two alpine species of Lepidoptera from Australia. For each species, the number of observations $(n)$ represents presences and true absences including pseudo-absences followed by presences and true absences only (Lomera caespitosae, $n=117$; Oncopera alpina, $n=149$ ). The values reflect the scores obtained from the R package GBM involving 10-fold cross-validation procedures on the entire observation dataset. Sensitivity $(S e)$ and specificity $(S p)$ are reported at the threshold that maximizes sensitivity + specificity. AUC, area under the receiver operating characteristic curve.

\begin{tabular}{|c|c|c|c|c|c|c|}
\hline Species & No. observations (mean) & No. trees (mean) & AUC & Threshold & $\mathrm{Se}$ & $S p$ \\
\hline L. caespitosae & $498-556(528)$ & $650-1200(955)$ & $0.98 \pm 0.00$ & $0.37 \pm 0.04$ & $1.00 \pm 0.01$ & $0.98 \pm 0.01$ \\
\hline L. caespitosae & 117 & 600-1900 (1165) & $0.84 \pm 0.02$ & $0.51 \pm 0.05$ & $0.95 \pm 0.03$ & $0.97 \pm 0.02$ \\
\hline O. alpina & $533-556(549)$ & $900-1150(980)$ & $0.99 \pm 0.00$ & $0.17 \pm 0.00$ & $1.00 \pm 0.00$ & $0.98 \pm 0.01$ \\
\hline O. alpina & 149 & $650-1150(855)$ & $0.95 \pm 0.01$ & $0.75 \pm 0.04$ & $0.93 \pm 0.01$ & $1.00 \pm 0.00$ \\
\hline
\end{tabular}

Table 2 Evaluation scores obtained for final models of two alpine species of Lepidoptera in Australia across $5 k$-fold partitions and evaluated using both area under the receiver operating characteristic curve (AUC) test (AUC TEST $_{\text {) }}$ and true skill statistic (TSS) scores obtained at the threshold of maximum sensitivity plus specificity. Within each partition, models were built with all data including pseudo-absence data, but then tested only on presences and true absences. Values for damage sites reflected the predictive ability of the final models constructed on the entire dataset against an independent test dataset, and were evaluated through $\mathrm{AUC}_{\mathrm{TEST}}$ across these sites as well as the omission error rate [sensitivity $(\mathrm{Se})-1]$.

\begin{tabular}{lllllll}
\hline Species & AUC $_{\text {TEST }}$ & Threshold & TSS & Se & AUC $_{\text {TEST }}$ (damage sites) & Omission error rate (damage sites) \\
\hline Lomera caespitosae & $0.82 \pm 0.01$ & $0.53 \pm 0.21$ & $0.59 \pm 0.13$ & $0.79 \pm 0.19$ & 0.92 & 0.17 \\
Oncopera alpina & $0.94 \pm 0.01$ & $0.78 \pm 0.18$ & $0.87 \pm 0.07$ & $0.89 \pm 0.07$ & 0.98 & 0.04 \\
\hline
\end{tabular}
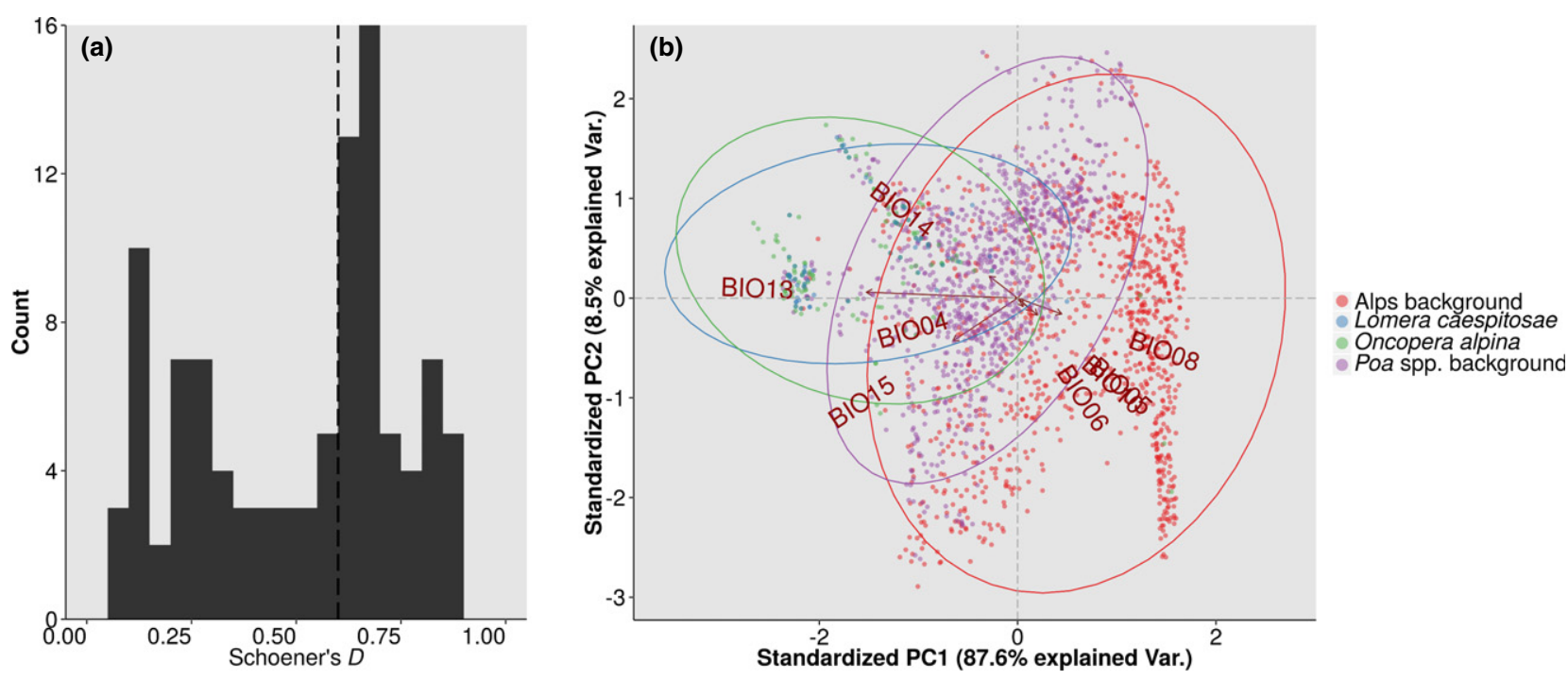

Figure 3 Environmental similarity between two Australian alpine Lepidoptera species, Lomera caespitosae and Oncopera alpina. (a) Histogram showing scores representing the expected degree of niche overlap (Schoener's D) when samples of L. caespitosae and O. alpina are drawn from the same distribution. The vertical dashed line indicates the observed overlap between species, while the histogram illustrates the distribution of overlaps from pseudo-replicates. The results indicate non-significant differences in the ecological niches for both moth species. (b) Principal components analysis (PCA) of eight environmental predictors at presence localities for $L$. caespitosae and O. alpina. The red dots are 1000 random samples across the alpine study area. The purple dots are 1000 random samples across the host-plant map (Poa costiniana, P. fawcettiae, P. hothamensis, P. hiemata and P. phillipsiana; Poa5). Principal component 1 (PC1) loadings are BIO13 (46.02\%), BIO15 (19.70\%) and BIO08 (13.44\%). Principal component 2 (PC2) loadings are BIO15 (35\%), BIO14 (17.78\%) and BIO05 (13.41\%) (see text for details). Ellipses represent 95\% probabilities of each grouping (dataset). Arrows indicate the importance and correlation of each bioclimatic variable on the two significant axes. Var., variance.

\section{Climate change responses}

Under the climate change scenarios investigated here, there was an overall trend of declining suitability for the host Poa spp. (see Figs S1 \& S4a in Appendices S1 \& S3, respectively). While the same decline was expected for both moth distributions, the species' responses differed, with models predicting further decline in suitability for L. caespitosae (Fig. 4, and see 


\section{+Host | -Host}

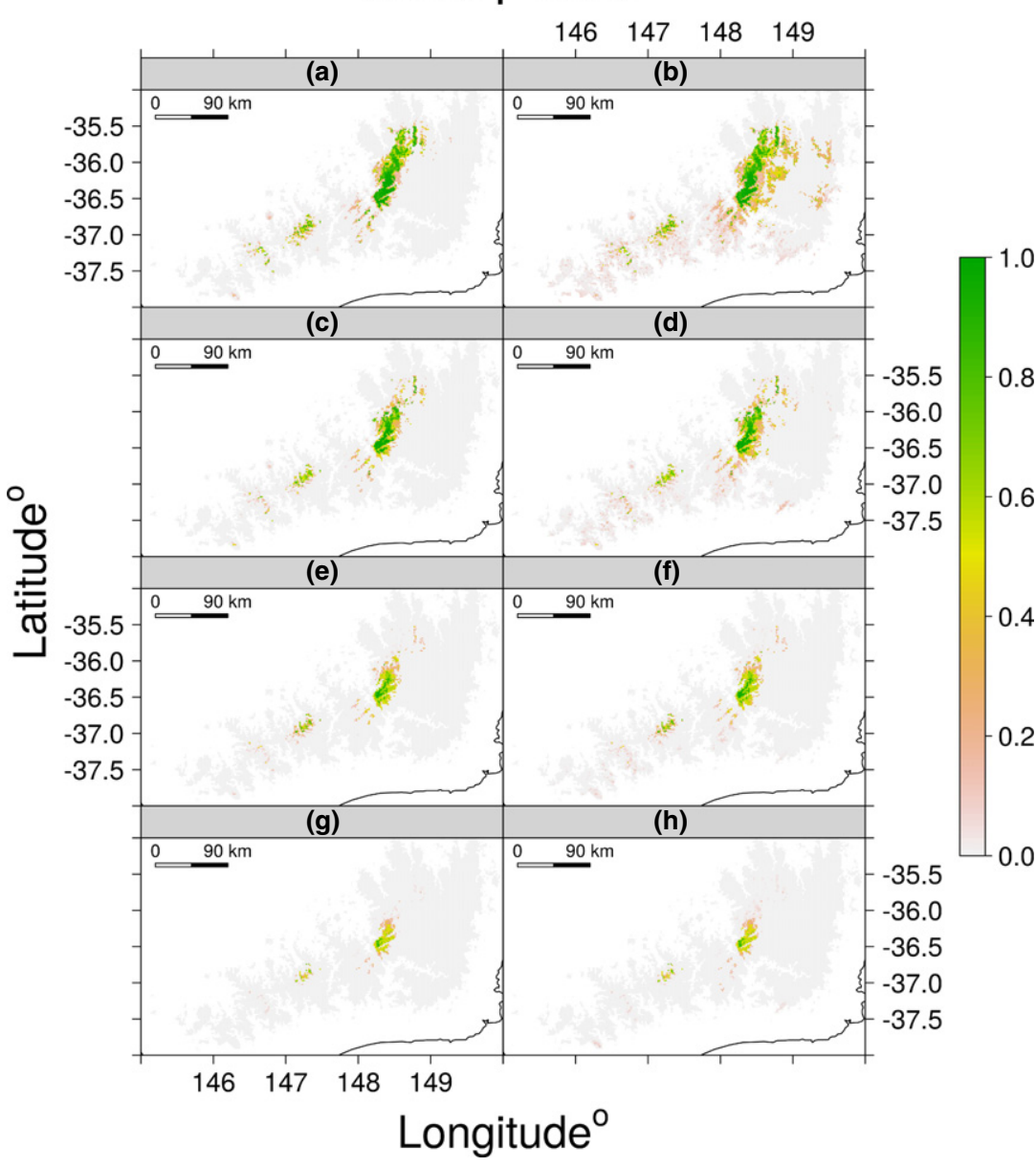

Figure 4 Predicted maps at 250-m resolution showing suitable habitat distribution for Lomera caespitosae, an alpine Lepidoptera species from Australia, (a) with and (b) without a background of the species' host-plant preference (three species of Poa, P. hiemata, P. costiniana and P. phillipsiana; Poa3), under current climatic space and future climatic space for (c, d) 2030, (e, f) 2050 and (g, h) 2070. The legend indicates suitability from 0 (not suitable) to 1 (perfect suitability). The rectangular box represents the extent of the predictor layers and the light grey area represents the elevation above $700 \mathrm{~m}$ a.s.l.

Fig. S4b in Appendix S3) than O. alpina (Fig. 5, and see Fig. S4c in Appendix S3). The declining suitability for both species was accompanied by decreased connectivity as a result of increased isolation of suitable habitats among mountain ranges within and between Victoria and NSW that continued through all future scenarios. The decline was relatively rapid for L. caespitosae by 2050, with populations in Mt Buller and associated regions in Victoria predicted to be lost, while those for O. alpina were predicted to persist. This trend continued for both species through to 2070, with L. caespitosae restricted to fewer isolated patches in the Victorian Alps than in the Kosciuszko area. Oncopera alpina on the other hand, appeared to be more restricted in range in the Kosciuszko area than in the Victorian Alps by 2070. Niche overlap scores between model predictions dependent and independent of host, for both species, under current and future climatic scenarios (Fig. S4b,c), supported the notion that suitable climate space is likely to decrease under climate change for both species. The presence of host plants altered this decline in L. caespitosae (Schoener's $D=0.7$, under baseline scenario) but the effect was not as pronounced as in O. alpina (Schoener's $D=0.9$, under baseline scenario), suggesting L. caespitosae is relatively more limited by host range than O. alpina.

\section{DISCUSSION}

We investigated the distribution of two insect herbivores and their host plants in an Australian alpine environment to determine factors potentially limiting the spatial distribution of these species and their responses under climate change. As in the case of the majority of European butterflies (Schweiger et al., 2012), we found that climate rather than host availability was the main factor limiting distributions. Observed distributions and ENM-predicted ranges of the moths were more restricted than those of the Poa hosts, occupying only a subset of the available climatic space (as indicated through PCA). This suggests that the ranges of alpine Lepidoptera are limited by climatic factors rather than host range.

As with other ENMs, our interpretations on current and future distributions for the moth herbivores are limited by certain model assumptions, such as invariant relationships in correlations between predictor variables and also between predictor and response variables throughout the entire time span until 2070. However, novel climate space may arise for a species under climate change and provide additional areas of refuge, or alternatively a faster rate of loss of suitable climate space than projected, and such novel scenarios have not been considered here (Williams et al., 2007). Similarly, 


\section{+Host | -Host}

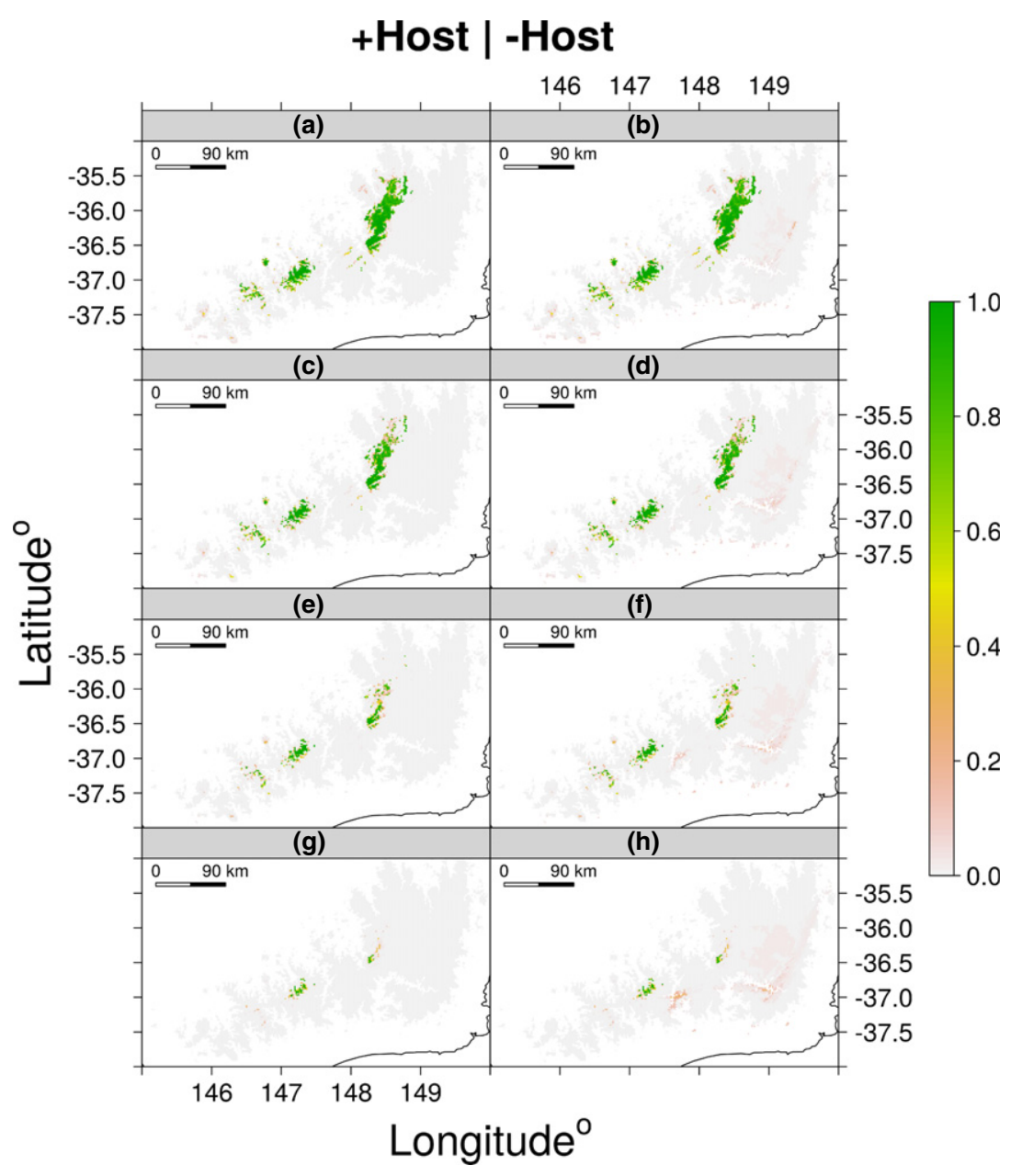

Figure 5 Predicted maps at $250-\mathrm{m}$ resolution showing suitable habitat distribution for Oncopera alpina, an alpine Lepidoptera species from Australia, (a) with and (b) without a background of the species' host-plant preference (five species of Poa, P. costiniana, P. fawcettiae, $P$. hothamensis, $P$. hiemata and $P$. phillipsiana; Poa5), under current climatic space and future climatic space for (c, d) 2030, (e, f) 2050 and $(\mathrm{g}, \mathrm{h})$ 2070. The legend indicates suitability from 0 (not suitable) to 1 (perfectly suitable). The rectangular box represents the extent of predictor layers and the light grey area represents the elevation above $700 \mathrm{~m}$ a.s.1.

our models are unable to account for plastic or evolutionary changes in physiological traits to counter stressful conditions under the climatic change projected for this area (Hoffmann \& Sgro, 2011). Lepidoptera from alpine areas may have physiological resilience, as reflected by an ability to acclimate as well as an ability to undergo local adaptation to different microclimates (Fischer \& Karl, 2010). These considerations also apply to the Poa host plants, which show potential for adaptation through plastic and genetic means based on transplant experiments (Byars et al., 2007) and phenological studies (Hoffmann et al., 2010).

An occurrence outlier (see Fig. S2a in Appendix S2) was detected in $L$. caespitosae in the relatively low-lying eastern alpine region. This outlier may reflect model under-prediction as a result of insufficient sampling of these types of environments, or perhaps a site with a microclimate suitable for moth persistence outside the core distribution. Beyond the rare geographical outliers, the ENMs predicted all other occurrence points, including the high plain region of Bimberi (ACT), as mentioned in Chadwick (1966) but not sampled here. Our models accurately predicted grass-damage sites for both moth species, providing an independent means of confirming the models. The moth species have overlapping distributions, with no detrimental effects of competition detected at the scale of the study employed here, supporting the notion that these species differ in their feeding and sheltering zones (White, 1948; Chadwick, 1966, 1969).

The different climatic factors influencing these moth species account for their range mismatch, as reflected in the niche overlap score (Schoener's $D=0.6$ ) and also the specific environmental space occupied by each species within the study area. The species differ in a number of biological and behavioural characteristics that may affect their climatic responses. For example, L. caespitosae larvae remain on aerial parts of the host for feeding and hibernate under snow on two occasions in their 2-year life cycle, while L. caespitosae adults emerge to lay eggs during the warmest quarter of the year (White, 1948). In contrast, O. alpina has an annual life cycle (M. Parida et al., unpublished data), and larvae shelter in underground soil tunnels where they are less likely to be exposed to climatic extremes.

The association between snow grass damage and the presence of the moth species remains unclear (Chadwick, 1966; Edwards, 2002). We were therefore particularly interested in testing whether records of damage matched the distribution of a particular species. We found that Poa damage sites tended to be found in areas where the distribution of the two species overlapped, although these areas were 
particularly suitable for $O$. alpina. Perhaps the presence of both species is required for high levels of damage to become evident.

In response to recent warming, large shifts in species ranges have already been observed in butterfly communities across Europe and North America (Parmesan et al., 1999; Breed et al., 2012). Our results support the prevailing view that climate limits the distribution of Lepidoptera at cool or higher latitude range margins (Schweiger et al., 2012). However, unlike in the Northern Hemisphere, higher elevations or latitudes are unavailable as climate refugia in Australia. The Australian Alps region has warmed at a rate of about $0.2{ }^{\circ} \mathrm{C}$ per decade from 1950 to 2001 (Hennessy et al., 2003; Wahren et al., 2013) and future predictions suggest continuously rising temperatures, with average temperatures predicted to increase by $+0.6{ }^{\circ} \mathrm{C}$ to $+2.9{ }^{\circ} \mathrm{C}$ by 2050 . These changes are expected to be accompanied by a reduction in snow cover and also a reduction in precipitation by up to 24\% compared with 1990 levels (Worboys \& Good, 2011). We found that the distributions of both host and herbivore species are projected to decline across time as conditions become unfavourable, consistent with the projected response of other cold-adapted animal and plant species in bioclimatic modelling studies (Brereton et al., 1995; Habel et al., 2011; Gottfried et al., 2012).

Habitat range and spatial connectivity is predicted to decline within and between mountain ranges in both species, which might limit gene flow between populations across disjunct and non-disjunct habitats, as has been observed in historically isolated habitats (Osborne et al., 2000; Igawa et al., 2013), particularly in species with poor dispersive abilities (Gaublomme et al., 2013). Climate space for both the moth species is expected to decline rapidly and become fragmented in the future. Such a range contraction will have wider effects because these herbivores contribute to the diversity of vegetation and associated fauna in the Australian Alps. For instance, by causing localized grass death, the moths create bare patches of ground that are essential for the colonization of shrubs and forbs (Williams et al., 2014). Our results also point to probable regional differences in climatic effects, with $L$. caespitosae at greater risk of extinction in the Victorian Alps and O. alpina at greater risk in the Kosciuszko region. However, the wider distribution of Poa spp. suggests that these species are more resistant to warming than their moth herbivores. Resilience of grassland communities to climate warming has been observed globally both in alpine and non-alpine areas (Pickering \& Armstrong, 2000; Vittoz et al., 2009; Craine et al., 2012), in contrast with vascular plant communities (Good, 2008; Gottfried et al., 2012).

In summary, our study indicates that the spatial distributions of two alpine Lepidoptera species are climatically driven and likely to be more affected than their host species under climate change scenarios. Lomera caespitosae is predicted to have a higher risk of range contraction than O. alpina. Snow grass damage appears to be associated with zones where these moth species' distributions overlap. If both moth species need to be present in an area to generate damage to grasslands, there is likely to be less damage in future years. There may also be other consequences of contracting moth species distributions in future years, particularly for local biodiversity.

\section{ACKNOWLEDGEMENTS}

The authors thank Jane Elith for providing climate data. Henrik Wahren, Warwick Papst, Michael Nash, Karen Stott, Elaine Thomas, Annie Leschen, James Shannon, Roger Good, Ken Green and Keith McDougall provided information on grass-damage sightings in Victoria and New South Wales. We appreciate and acknowledge field assistance from Michael Nash and Citra Jewson Brown in recording moth presence-absence data in New South Wales. Thanks also to Vincent Q. Vu for making accessible his ggbiplot functions used to create Fig. 3b. No conflict of interest exists among the authors. The work was supported by funding through the Long Term Ecological Research Network and the Linkage/Laureate Fellowship programmes of the Australian Research Council, with the Victorian Department of the Environment and Primary Industry and Parks Victoria as partners.

\section{REFERENCES}

Allouche, O., Tsoar, A. \& Kadmon, R. (2006) Assessing the accuracy of species distribution models: prevalence, kappa and the true skill statistic (TSS). Journal of Applied Ecology, 43, 1223-1232.

Araújo, M.B. \& Luoto, M. (2007) The importance of biotic interactions for modelling species distributions under climate change. Global Ecology and Biogeography, 16, 743753.

Araújo, M.B. \& Rozenfeld, A. (2014) The geographic scaling of biotic interactions. Ecography, 37, 406-415.

Araújo, M.B., Thuiller, W., Williams, P.H. \& Reginster, I. (2005) Downscaling European species atlas distributions to a finer resolution: implications for conservation planning. Global Ecology and Biogeography, 14, 17-30.

Barea-Azcón, J.M., Benito, B.M., Olivares, F.J., Ruiz, H., Martín, J., García, A.L. \& López, R. (2014) Distribution and conservation of the relict interaction between the butterfly Agriades zullichi and its larval foodplant (Androsace vitaliana nevadensis). Biodiversity and Conservation, 23, 927-944.

Barve, N., Barve, V., Jiménez-Valverde, A., Lira-Noriega, A., Maher, S.P., Peterson, A.T., Soberón, J. \& Villalobos, F. (2011) The crucial role of the accessible area in ecological niche modelling and species distribution modelling. Ecological Modelling, 222, 1810-1819.

Breed, G.A., Stichter, S. \& Crone, E.E. (2012) Climate-driven changes in north-eastern US butterfly communities. Nature Climate Change, 3, 142-145. 
Brereton, R., Bennett, S. \& Mansergh, I. (1995) Enhanced greenhouse climate change and its potential effect on selected fauna of south-eastern Australia: a trend analysis. Biological Conservation, 72, 339-354.

Buston, P.M. \& Elith, J. (2011) Determinants of reproductive success in dominant pairs of clownfish: a boosted regression tree analysis. Journal of Animal Ecology, 80, 528-538.

Byars, S.G., Papst, W. \& Hoffmann, A.A. (2007) Local adaptation and co-gradient selection in the alpine plant, Poa hiemata, along a narrow altitudinal gradient. Evolution, 61, 2925-2941.

Carr, S.G.M. \& Turner, J.S. (1959) The ecology of the Bogong High Plains. I. The environmental factors and the grassland communities. Australian Journal of Botany, 7, 12-33.

Chadwick, C.E. (1966) Investigations on Plutorectis caespitosae Oke (Lep., Psychidae) and Oncopera alpina Tindale (Lep., Hepialidae), in the Australian Alps. Journal of the Entomological Society of Australia (NSW), 3, 5-29.

Chadwick, C.E. (1969) Two species of caterpillar injurious to snow grass (Poa spp.) in the Australian Alps. Agricultural Gazette New South Wales, 80, 626-628.

Craine, J.M., Ocheltree, T.W., Nippert, J.B., Towne, E.G., Skibbe, A.M., Kembel, S.W. \& Fargione, J.E. (2012) Global diversity of drought tolerance and grassland climatechange resilience. Nature Climate Change, 3, 63-67.

Edwards, E.D. (2002) Lepidoptera (moths and butterflies). Biodiversity in the Snowy Mountains (ed. by K. Green), pp. 58-72. Australian Institute of Alpine Studies, Jindabyne, NSW.

Elith, J. \& Leathwick, J.R. (2009) Species distribution models: ecological explanation and prediction across space and time. Annual Review of Ecology, Evolution, and Systematics, 40, 677-697.

Elith, J., Leathwick, J.R. \& Hastie, T. (2008) A working guide to boosted regression trees. Journal of Animal Ecology, 77, 802-813.

Elith, J., Phillips, S.J., Hastie, T., Dudík, M., Chee, Y.E. \& Yates, C.J. (2011) A statistical explanation of Maxent for ecologists. Diversity and Distributions, 17, 43-57.

Eskildsen, A., le Roux, P.C., Heikkinen, R.K., Høye, T.T., Kissling, W.D., Pöyry, J., Wisz, M.S. \& Luoto, M. (2013) Testing species distribution models across space and time: high latitude butterflies and recent warming. Global Ecology and Biogeography, 22, 1293-1303.

Fischer, K. \& Karl, I. (2010) Exploring plastic and genetic responses to temperature variation using copper butterflies. Climate Research, 43, 17-30.

Gaublomme, E., Maebe, K., Van Doninck, K., Dhuyvetter, H., Li, X., Desender, K. \& Hendrickx, F. (2013) Loss of genetic diversity and increased genetic structuring in response to forest area reduction in a ground dwelling insect: a case study of the flightless carabid beetle Carabus problematicus (Coleoptera, Carabidae). Insect Conservation and Diversity, 6, 473-482.
Good, R. (2008) The impacts of climate change on the alpine biota: management adaptations in the Australian Alps. Mountain Forum Bulletin, January, 2008, 9-11.

Gottfried, M., Pauli, H., Futschik, A. et al. (2012) Continentwide response of mountain vegetation to climate change. Nature Climate Change, 2, 111-115.

Green, K. \& Osborne, W.S. (1994) Wildlife of the Australian snow-country: a comprehensive guide to alpine fauna. Reed Books, Chatswood, NSW.

Habel, J.C., Rödder, D., Schmitt, T. \& Nève, G. (2011) Global warming will affect the genetic diversity and uniqueness of Lycaena helle populations. Global Change Biology, 17, 194-205.

Hanspach, J., Schweiger, O., Kühn, I., Plattner, M., Pearman, P.B., Zimmermann, N.E. \& Settele, J. (2014) Host plant availability potentially limits butterfly distributions under cold environmental conditions. Ecography, 37, 301-308.

Heikkinen, R.K., Luoto, M., Virkkala, R., Pearson, R.G. \& Körber, J.-H. (2007) Biotic interactions improve prediction of boreal bird distributions at macro-scales. Global Ecology and Biogeography, 16, 754-763.

Hennessy, K.J., Whetton, P., Smith, I., Bathols, J., Hutchinson, M. \& Sharples, J. (2003) The impact of climate change on snow conditions in mainland Australia. CSIRO Atmospheric Research, 47, 1-50.

Hijmans, R.J., Phillips, S., Leathwick, J. \& Elith, J. (2013) Package 'dismo'. species distribution modeling. R package version 1.0-5. Available at: http://CRAN.R-project.org/ package $=$ dismo.

Hill, M.P., Hoffmann, A.A., Macfadyen, S., Umina, P.A. \& Elith, J. (2012) Understanding niche shifts: using current and historical data to model the invasive redlegged earth mite, Halotydeus destructor. Diversity and Distributions, 18, 191-203.

Hodkinson, I.D. \& Bird, J. (1998) Host-specific insect herbivores as sensors of climate change in arctic and alpine environments. Arctic and Alpine Research, 30, 78-83.

Hof, A.R., Jansson, R. \& Nilsson, C. (2012) How biotic interactions may alter future predictions of species distributions: future threats to the persistence of the arctic fox in Fennoscandia. Diversity and Distributions, 18, 554-562.

Hoffmann, A.A. \& Sgro, C.M. (2011) Climate change and evolutionary adaptation. Nature, 470, 479-485.

Hoffmann, A.A., Camac, J.S., Williams, R.J., Papst, W., Jarrad, F.C. \& Wahren, C.-H. (2010) Phenological changes in six Australian subalpine plants in response to experimental warming and year-to-year variation. Journal of Ecology, 98, 927-937.

Hughes, L. (2011) Climate change and Australia: key vulnerable regions. Regional Environmental Change, 11, 189-195.

Igawa, T., Oumi, S., Katsuren, S. \& Sumida, M. (2013) Population structure and landscape genetics of two endangered frog species of genus Odorrana: different scenarios on two islands. Heredity, 110, 46-56.

IPCC (2007) Climate change 2007: synthesis report. Contribution of Working Groups I, II and III to the Fourth 
Assessment Report of the Intergovernmental Panel on Climate Change (ed. by Core Writing Team, R. K. Pachauri and A. Reisinger). Intergovernmental Panel on Climate Change (IPCC), Geneva.

Jaeschke, A., Bittner, T., Reineking, B. \& Beierkuhnlein, C. (2013) Can they keep up with climate change? Integrating specific dispersal abilities of protected Odonata in species distribution modelling. Insect Conservation and Diversity, 6, 93-103.

Liu, C., White, M. \& Newell, G. (2013) Selecting thresholds for the prediction of species occurrence with presence-only data. Journal of Biogeography, 40, 778-789.

McKeown, K.C. (1951) Field notes on some insects of the Mount Kosciusko area. Australian Zoologist, 2, 333-337.

Mellin, C., Russell, B.D., Connell, S.D., Brook, B.W. \& Fordham, D.A. (2012) Geographic range determinants of two commercially important marine molluscs. Diversity and Distributions, 18, 133-146.

Osborne, P.E. \& Leitão, P.J. (2009) Effects of species and habitat positional errors on the performance and interpretation of species distribution models. Diversity and Distributions, 15, 671-681.

Osborne, M.J., Norman, J.A., Christidis, L. \& Murray, N.D. (2000) Genetic distinctness of isolated populations of an endangered marsupial, the mountain pygmy-possum, Burramys parvus. Molecular Ecology, 9, 609-613.

Parmesan, C., Ryrholm, N., Stefanescu, C., Hill, J.K., Thomas, C.D., Descimon, H., Huntley, B., Kaila, L., Kullberg, J., Tammaru, T., Tennent, W.J., Thomas, J.A. \& Warren, M. (1999) Poleward shifts in geographical ranges of butterfly species associated with regional warming. Nature, 399, 579-583.

Parolo, G., Rossi, G. \& Ferrarini, A. (2008) Toward improved species niche modelling: Arnica montana in the Alps as a case study. Journal of Applied Ecology, 45, 14101418.

Phillips, S. (2010) A brief tutorial on Maxent. Lessons in Conservation, 3, 107-135.

Pickering, C.M. \& Armstrong, T. (2000) Climate change and the plant communities of the Kosciuszko Alpine zone in the Australian Alps. Griffith University, QLD, CRC for Sustainable Tourism.

R Core Team (2013) R: a language and environment for statistical computing. R Foundation for Statistical Computing, Vienna, Austria. Available at: http://www.r-project.org/.

Randin, C.F., Engler, R., Normand, S., Zappa, M., Zimmermann, N.E., Pearman, P.B., Vittoz, P., Thuiller, W. \& Guisan, A. (2009) Climate change and plant distribution: local models predict high-elevation persistence. Global Change Biology, 15, 1557-1569.

Rasmann, S., Pellissier, L., Defossez, E., Jactel, H. \& Kunstler, G. (2014) Climate-driven change in plant-insect interactions along elevation gradients. Functional Ecology, 28, 46-54.

Ridgeway, G. et al. (2013) gbm: generalized boosted regression models. R package version 2.1. Available at: http:// CRAN.R-project.org/package $=\mathrm{gbm}$.
Rinnhofer, L.J., Roura-Pascual, N., Arthofer, W., Dejaco, T., Thaler-Knoflach, B., Wachter, G.A., Christian, E., Steiner, F.M. \& Schlick-Steiner, B.C. (2012) Iterative species distribution modelling and ground validation in endemism research: an Alpine jumping bristletail example. Biodiversity and Conservation, 21, 2845-2863.

Schweiger, O., Heikkinen, R.K., Harpke, A., Hickler, T., Klotz, S., Kudrna, O., Kühn, I., Pöyry, J. \& Settele, J. (2012) Increasing range mismatching of interacting species under global change is related to their ecological characteristics. Global Ecology and Biogeography, 21, 88-99.

Thuiller, W., Guéguen, M., Georges, D., Bonet, R., Chalmandrier, L., Garraud, L., Renaud, J., Roquet, C., Van Es, J., Zimmermann, N.E. \& Lavergne, S. (2014) Are different facets of plant diversity well protected against climate and land cover changes? A test study in the French Alps. Ecography, 37, 1-13.

Van der Putten, W.H., Macel, M. \& Visser, M.E. (2010) Predicting species distribution and abundance responses to climate change: why it is essential to include biotic interactions across trophic levels. Philosophical Transactions of the Royal Society B: Biological Sciences, 365, 2025-2034.

Vittoz, P., Randin, C., Dutoit, A., Bonnet, F. \& Hegg, O. (2009) Low impact of climate change on subalpine grasslands in the Swiss Northern Alps. Global Change Biology, 15, 209-220.

Wahren, C.-H., Camac, J.S., Jarrad, F.C., Williams, R.J., Papst, W.A. \& Hoffmann, A.A. (2013) Experimental warming and long-term vegetation dynamics in an alpine heathland. Australian Journal of Botany, 61, 36-51.

Walsh, N.G. \& Entwisle, T.J. (1994) Flora of Victoria, Vol. 2, Ferns and allied plants, conifers and monocotyledons. Royal Botanic Gardens Inkata Press, Melbourne.

Walther, G.-R. (2010) Community and ecosystem responses to recent climate change. Philosophical Transactions of the Royal Society B: Biological Sciences, 365, 2019-2024.

Walther, G.-R., Beißner, S. \& Burga, C.A. (2005) Trends in the upward shift of Alpine plants. Journal of Vegetation Science, 16, 541-548.

Warren, D.L., Glor, R.E., Turelli, M. \& Funk, D. (2008) Environmental niche equivalency versus conservatism: quantitative approaches to niche evolution. Evolution, 62, 2868-2883.

Warren, D.L., Glor, R.E. \& Turelli, M. (2010) ENMTools: a toolbox for comparative studies of environmental niche models. Ecography, 33, 607-611.

White, L.D. (1948) Investigation concerning a new species of Psychid (or case-moth) Plutorectis caespitosae causing damage to alpine pasture. Master's Thesis, University of Melbourne, Melbourne.

Williams, J.W., Jackson, S.T. \& Kutzbach, J.E. (2007) Projected distributions of novel and disappearing climates by 2100 AD. Proceedings of the National Academy of Sciences USA, 104, 5738-5742.

Williams, R.J., Papst, W.A., McDougall, K.L., Mansergh, I.M., Heinze, D., Camac, J.S., Nash, M.A., Morgan, J.W. \& 
Hoffmann, A.A. (2014) Alpine ecosystems. Biodiversity and environmental change: monitoring, challenges and direction (ed. by D. Lindenmayer, E. Burns, N. Thurgate and A. Lowe), pp. 169-214. CSIRO Publishing, Melbourne.

Willis, K.J. \& Bhagwat, S.A. (2009) Biodiversity and climate change. Ecology, 326, 806-807.

Wilson, A. (2009) Flora of Australia, Vol. 44A, Poaceae 2. CSIRO Publishing, Australian Biological Resources Study, Canberra.

Wisz, M.S., Pottier, J., Kissling, W.D. et al. (2013) The role of biotic interactions in shaping distributions and realised assemblages of species: implications for species distribution modelling. Biological Reviews, 88, 15-30.

Worboys, G.L. \& Good, R.B. (2011) Caring for our Australian Alps catchments: summary report for policy makers. Department of Climate Change and Energy Efficiency, Canberra.

\section{SUPPORTING INFORMATION}

Additional Supporting Information may be found in the online version of this article:

Appendix S1 Creating Poa spp. maps (includes Fig. S1).

Appendix S2 Mapped point locations of Poa spp. damage sites and moth occurrences (Fig. S2).

Appendix S3 Species response to climate variables (Figs S3 \& S4).

\section{DATA ACCESSIBILITY}

Complete presence and absence distribution data for the two moth species are available on figshare: http://dx.doi.org/ 10.6084/m9.figshare. 1246840

\section{BIOSKETCHES}

Manaswini Parida is a $\mathrm{PhD}$ student focusing on native Australian alpine Lepidoptera species and their role in sporadic snow grass deaths in the Australian Alps.

Ary Hoffmann works on environmental stress adaptation, focusing mainly on invertebrates and climate change.

Matt Hill has research interests in ecophysiology and species distribution modelling of terrestrial invertebrates with regard to invasion biology and climate change response.

Author contributions: M.P. collected the data; M.P. and M.P.H. analysed the data; A.A.H. conceived the idea and guided the study; all authors contributed to the writing.

Editor: Miles Silman 